Case Reports in
Gastroenterology
Case Rep Gastroenterol 2020;14:338-345

DOI: 10.1159/000508414
Published online: July 22, 2020

(C) 2020 The Author(s)

Published by S. Karger AG, Basel www.karger.com/crg

This article is licensed under the Creative Commons Attribution-NonCommercial 4.0 International License (CC BY-NC) (http://www.karger.com/Services/OpenAccessLicense). Usage and distribution for commercial purposes requires written permission.

\title{
Gastric Metastasis from Colorectal Cancer Mimicking a Submucosal Tumor
}

\author{
Naoto Iwai ${ }^{a, b}$ Takashi Okuda ${ }^{a}$ Taishi Harada ${ }^{c}$ Kohei Oka ${ }^{a}$ \\ Tasuku Hara $^{\mathrm{a}}$ Yutaka Inada $^{\mathrm{b}}$ Toshifumi Tsuji $^{\mathrm{a}}$ Toshiyuki Komaki $^{\mathrm{a}}$ \\ Osamu Dohi ${ }^{\mathrm{b}}$ Naohisa Yoshida ${ }^{\mathrm{b}}$ Hideyuki Konishib ${ }^{\mathrm{b}}$ Yuji Naito $^{\mathrm{b}}$ \\ Yoshito Itoh $^{\mathrm{b}}$ Keizo Kagawa ${ }^{\mathrm{a}} \mathrm{b}$ \\ ${ }^{a}$ Department of Gastroenterology and Hepatology, Fukuchiyama City Hospital, \\ Fukuchiyama-City, Japan; 'bepartment of Molecular Gastroenterology and Hepatology, \\ Graduate School of Medical Science, Kyoto Prefectural University of Medicine, \\ Kyoto, Japan; 'Department of Medical Oncology, Fukuchiyama City Hospital, \\ Fukuchiyama-City, Japan
}

\section{Keywords}

Colorectal cancer · Gastric metastasis · Metastatic tumor · Signet-ring cell carcinoma

\begin{abstract}
Signet-ring cell carcinoma, a colorectal cancer (CRC) subtype, sometimes shows metastases to uncommon metastatic sites. However, gastric metastasis is extremely rare. Here, we describe a case of gastric metastasis from colonic cancer. A 76-year-old woman presented with anemia. Colonoscopic biopsy revealed a CRC on the transverse colon showing a poorly differentiated adenocarcinoma with a partial component of the signet-ring carcinoma. Computed tomography revealed multiple subcutaneous nodules on her chest and back, and a tumor in the left lower lobe of her lung. Esophagogastroduodenoscopy showed a submucosal tumor-like lesion in the upper gastric body, and endoscopic biopsy revealed the poorly differentiated adenocarcinoma along with the partial component of the signet-ring carcinoma as well as the colonic, subcutaneous, and pulmonary lesion. The findings of endoscopic and microscopic examinations revealed gastric metastasis from CRC on the transverse colon. A systemic chemotherapy was given, and the biopsy conducted 1 year after the initial chemotherapy revealed
\end{abstract}




\section{Case Reports in Gastroenterology}

Case Rep Gastroenterol 2020;14:338-345

DOI: $10.1159 / 000508414$

c) 2020 The Author(s). Published by S. Karger AG, Basel www.karger.com/crg

Iwai et al.: Gastric Metastasis from Colorectal Cancer Mimicking a Submucosal Tumor

no evidence of the residual tumor tissue in the gastric lesion. However, best supportive care was recommended depending on metastasis to the rectum. Our case suggests that gastric metastases from CRC should be considered in patients with lesions resembling a submucosal tumor accompanied by central depression and erosion.

\section{Introduction}

Colorectal cancer (CRC) is the second leading cause of cancer incidence and the third most common cause of cancer death worldwide [1]. Approximately $20 \%$ of the CRC cases present as stage IV [2,3], with most cases involving metastases to the liver, lung, and peritoneum tissues $[3,4]$. Although less common, CRC may also show metastasis to the stomach tissue. At present, the clinical features of gastric metastasis from CRC remains unclear.

CRC showing common adenocarcinoma causes liver metastases more frequently than that showing mucinous or signet-ring cell carcinoma. On the other hand, metastasis to rare sites is detected more frequently in CRC showing signet-ring cell carcinoma. Regarding histological type, signet-ring cell carcinoma has the potential to metastasize to uncommon metastasis sites in patients with CRC [5], signifying the importance of evaluating these sites when the histological type of CRC indicates signet-ring cell carcinoma.

Herein, we describe a case of CRC with a component of signet-ring cell carcinoma metastasizing to the gastric body and present literature reviews.

\section{Case Presentation}

A 76-year-old woman with a medical history of immunoglobulin A nephropathy presented with anemia in September 2018. Physical examination of the patients revealed conjunctival pallor and emaciation without abdominal pain. Laboratory tests showed a decreased hemoglobin level $(6.6 \mathrm{~g} / \mathrm{dL})$, total protein $(6.4 \mathrm{~g} / \mathrm{L})$, and albumin $(3.4 \mathrm{~g} / \mathrm{L})$, and increased levels of creatinine $(1.57 \mathrm{mg} / \mathrm{dL})$ and carcinoembryonic antigen $(53.5 \mathrm{ng} / \mathrm{mL})$. Computed tomography images revealed multiple subcutaneous nodules on her chest and back, and a tumor in the left lower lobe of her lung. Because of severe anemia, she underwent colonoscopy and esophagogastroduodenoscopy (EGD). Colonoscopy showed an ulcerative tumor in the transverse colon (Fig. 1), and EGD revealed a 2-cm lesion resembling a submucosal tumor in the upper gastric body at the lesser curve (Fig. 2a, b). Biopsy showed a poorly differentiated adenocarcinoma with a partial component of the signet-ring carcinoma (Fig. 3a). The normal and smooth surface covered the tumor accompanied by central depression and erosion. Endoscopic ultrasonography demonstrated that the lesion was mainly located in the submucosa and propria muscularis (Fig. 2c). The biopsy specimen from the gastric lesion also revealed the poorly differentiated adenocarcinoma along with the partial component of the signet-ring carcinoma (Fig. 3b) as well as the colonic, subcutaneous (Fig. 3c), and pulmonary lesion (Fig. $3 d$ ). In addition, immunohistochemistry showed a positive result for cytokeratin 20 in all specimens (Fig. 4a-d) and a negative result for thyroid transcription factor-1 (Fig. 4e) and surfactant Protein A (Fig. 4f) in the pulmonary lesion. The findings of endoscopic and microscopic examinations revealed gastric metastasis from CRC on the transverse colon. A systemic chemotherapy was given by our medical oncology department in November of 2018. Additional EGDs were conducted 6 months and 1 year after chemotherapy initiation, and they showed a significant reduction in the gastric lesion. A final biopsy conducted 1 year after the 


\section{Case Reports in Gastroenterology}

Case Rep Gastroenterol 2020;14:338-345 DOI: 10.1159/000508414

(c) 2020 The Author(s). Published by S. Karger AG, Basel www.karger.com/crg

Iwai et al.: Gastric Metastasis from Colorectal Cancer Mimicking a Submucosal Tumor

initial chemotherapy revealed no evidence of the residual tumor tissue. However, best supportive care was recommended depending on metastasis to the rectum.

\section{Discussion and Conclusion}

Gastric metastasis from CRC is extremely rare with only a few cases of gastric metastasis described in the medical literature [6-10]. In our case, the endoscopic findings of gastric metastasis from CRC were precisely clarified. A previous report showed that $5.4 \%$ of the autopsied patients with solid tumors had gastric metastases, and half of all gastric metastases resembled submucosal tumors, whereas the most common parts for primary sites in gastric metastases were the lung, breast, and esophagus [11]. Another report showed the characteristic endoscopic appearance as a small solitary nodule in the middle or upper third, with the most common being breast, lung, and malignant melanoma [12]. Typical endoscopic features of gastric metastasis include a submucosal tumor and polypoid lesions with central depression [13]. While our case also showed that the endoscopic appearance resembled a submucosal tumor accompanied by central depression and erosion, CRC as a primary site was extremely rare with reference to previous studies [11,12].

While the pathogenesis of gastric metastasis from CRC remains unclear, a previous study revealed that the metastatic sites could vary with the histological types of common, mucinous, and signet-ring cell carcinoma [5]. Patients with CRC who have common adenocarcinoma have liver metastases more frequently than those with mucinous or signet-ring cell carcinoma. On the other hand, those with mucinous or signet-ring cell carcinoma have peritoneal metastases more frequently than those with common adenocarcinoma. Furthermore, metastasis to rare sites such as the bone, pancreas, skin, and heart was detected more frequently in patients with CRC who had signet-ring cell carcinoma. Our case also showed a component of signet-ring cell carcinoma. This histological type of signet-ring cell carcinoma could demonstrate gastric metastasis. Previously, there has been a case of gastric metastases arising from signet-ring cell carcinoma of the colon similar to this case [11]. On the other hand, CRC with a well-differentiated adenocarcinoma was also reported to cause gastric metastases [6]. Owing to the lack of multiscale investigation, the biological characterization of gastric metastases from CRC remains unknown; however, histological subtype such as signet-ring cell carcinoma may affect the possibility of metastases at uncommon sites including the stomach.

In conclusion, this case could provide a better understanding of the clinical features of gastric metastasis from CRC. Gastric metastases from CRC should be considered for evaluation in patients presenting with lesions resembling a submucosal tumor accompanied by central depression and erosion.

\section{Acknowledgement}

We thank all members of the Department of Gastroenterology and Hepatology, Fukuchiyama City Hospital, and all members of the Department of Molecular Gastroenterology and Hepatology, Graduate School of Medical Science, Kyoto Prefectural University of Medicine. 


\section{Case Reports in Gastroenterology}

Iwai et al.: Gastric Metastasis from Colorectal Cancer Mimicking a Submucosal Tumor

\section{Statement of Ethics}

Written informed consent for publication was obtained from the patient.

\section{Conflict of Interest Statement}

The authors declare that they have no conflicts of interest.

\section{Funding Sources}

The authors did not receive any funding.

\section{Author Contributions}

Naoto Iwai, Takashi Okuda, Taishi Harada, Kohei Oka, Tasuku Hara, Yutaka Inada, Toshifumi Tsuji, Toshiyuki Komaki, and Keizo Kagawa carried out the diagnosis and treatment and contributed to the design of the report. Naoto Iwai, Osamu Dohi, and Naohisa Yoshida drafted the manuscript. Hideyuki Konishi, Yuji Naito, Yoshito Itoh, and Keizo Kagawa critically reviewed the draft. All authors approved the final version of the manuscript.

\section{References}

1 Bray F, Ferlay J, Soerjomataram I, Siegel RL, Torre LA, Jemal A. Global cancer statistics 2018: GLOBOCAN estimates of incidence and mortality worldwide for 36 cancers in 185 countries. CA Cancer J Clin. 2018 Nov;68(6):394-424.

2 Cook AD, Single R, McCahill LE. Surgical resection of primary tumors in patients who present with stage IV colorectal cancer: an analysis of surveillance, epidemiology, and end results data, 1988 to 2000. Ann Surg Oncol. 2005 Aug;12(8):637-45.

3 van der Geest LG, Lam-Boer J, Koopman M, Verhoef C, Elferink MA, de Wilt JH. Nationwide trends in incidence, treatment and survival of colorectal cancer patients with synchronous metastases. Clin Exp Metastasis. 2015 Jun;32(5):457-65.

4 Riihimäki M, Hemminki A, Sundquist J, Hemminki K. Patterns of metastasis in colon and rectal cancer. Sci Rep. 2016 Jul;6(1):29765.

5 Hugen N, van de Velde CJ, de Wilt JH, Nagtegaal ID. Metastatic pattern in colorectal cancer is strongly influenced by histological subtype. Ann Oncol. 2014 Mar;25(3):651-7.

6 Yoshimi F, Asato Y, Suzuki A, Kiyoshima M, Shioyama Y, Imura J, et al. Long-term survival after repeat resections of metastases in liver, lung, and stomach from sigmoid colon cancer: report of a case. Surg Today. 2007;37(1):53-60.

7 Wang PC, Wang CC, Hsu CS, Yue CT, Chen JH. Colon cancer with gastric invasion mimicking gastric submucosal tumor. Gastrointest Endosc. 2012 Jul;76(1):190-2.

8 Li B, Li Q, Li X, Zhang G, Shen L. Signet-ring cell cancer of the colon presenting as facial and gastroduodenal metastasis 7 years after sigmoidectomy. Endoscopy. 2014;46 Suppl 1 UCTN:E220-1. https://doi.org/10.1055/s-0034-1365151.

9 Nushijima Y, Nakano K, Sugimoto K, Nakaguchi K, Kan K, Maruyama H, et al. [A case of metastatic gastric cancer originating from transverse colon cancer]. Gan To Kagaku Ryoho. 2014 Nov;41(12):1802-4.

10 Terashima S, Watanabe S, Kogure M, Tanaka M. Long-term survival after resection of a gastric metastasis from transverse colon cancer: a case report. Fukushima J Med Sci. 2019 Aug;65(2):37-42.

11 Oda KH, Kondo H, Yamao T, Saito D, Ono H, Gotoda T, et al. Metastatic tumors to the stomach: analysis of 54 patients diagnosed at endoscopy and 347 autopsy cases. Endoscopy. 2001 Jun;33(6):507-10.

12 De Palma GD, Masone S, Rega M, Simeoli I, Donisi M, Addeo P, et al. Metastatic tumors to the stomach: clinical and endoscopic features. World J Gastroenterol. 2006 Dec;12(45):7326-8. 
Case Reports in Gastroenterology
Case Rep Gastroenterol 2020;14:338-345

DOI: $10.1159 / 000508414$

(c) 2020 The Author(s). Published by S. Karger AG, Basel www.karger.com/crg

Iwai et al.: Gastric Metastasis from Colorectal Cancer Mimicking a Submucosal Tumor

13 Hsu CC, Chen JJ, Changchien CS. Endoscopic features of metastatic tumors in the upper gastrointestinal tract. Endoscopy. 1996 Feb;28(2):249-53.
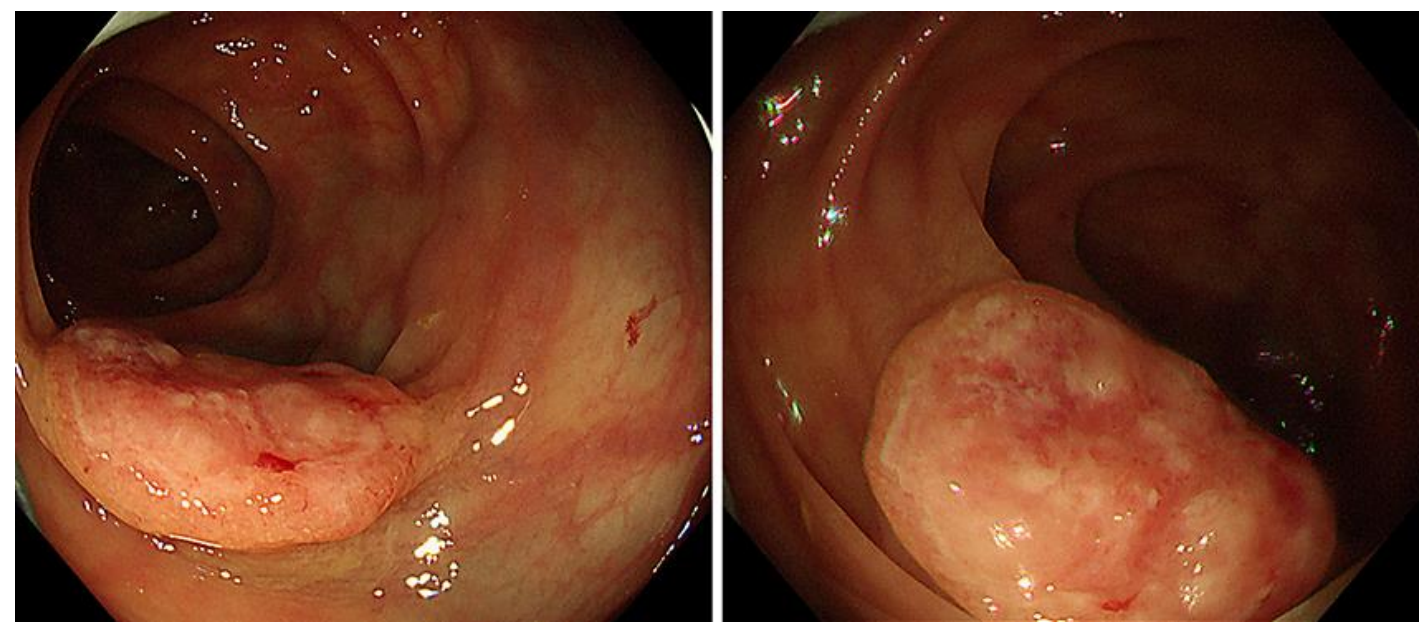

Fig. 1. Colonoscopic findings. An ulcerative tumor $3 \mathrm{~cm}$ in size in the transverse colon. 
Case Reports in Gastroenterology
Case Rep Gastroenterol 2020;14:338-345

DOI: 10.1159/000508414

(c) 2020 The Author(s). Published by S. Karger AG, Basel www.karger.com/crg

Iwai et al.: Gastric Metastasis from Colorectal Cancer Mimicking a Submucosal Tumor
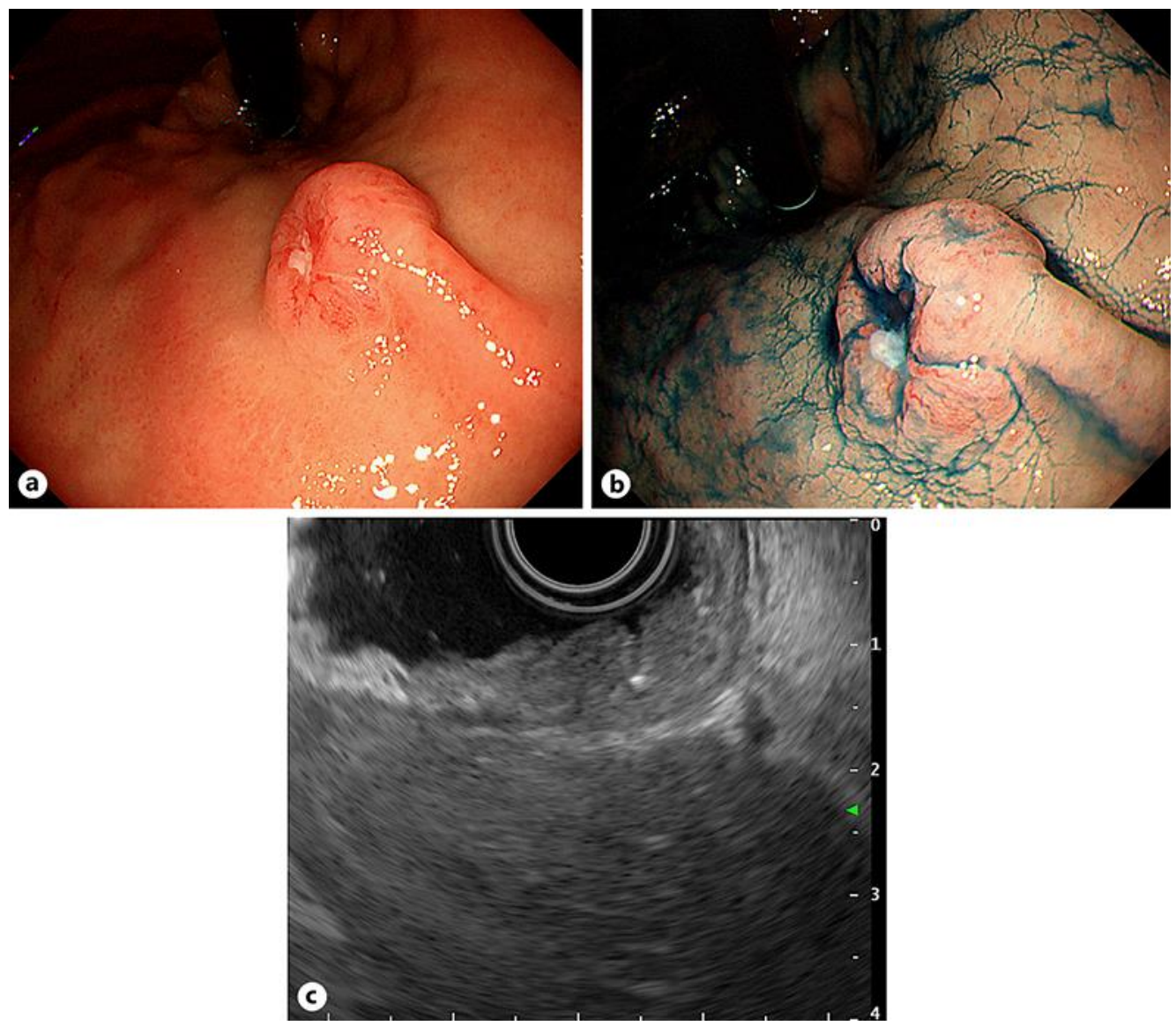

Fig. 2. EGD findings. EGD shows a 2-cm lesion resembling a submucosal tumor in the upper gastric body at the lesser curve $(\mathbf{a}, \mathbf{b})$. Endoscopic ultrasonography demonstrates that the lesion is mainly located in the submucosa and propria muscularis (c). 

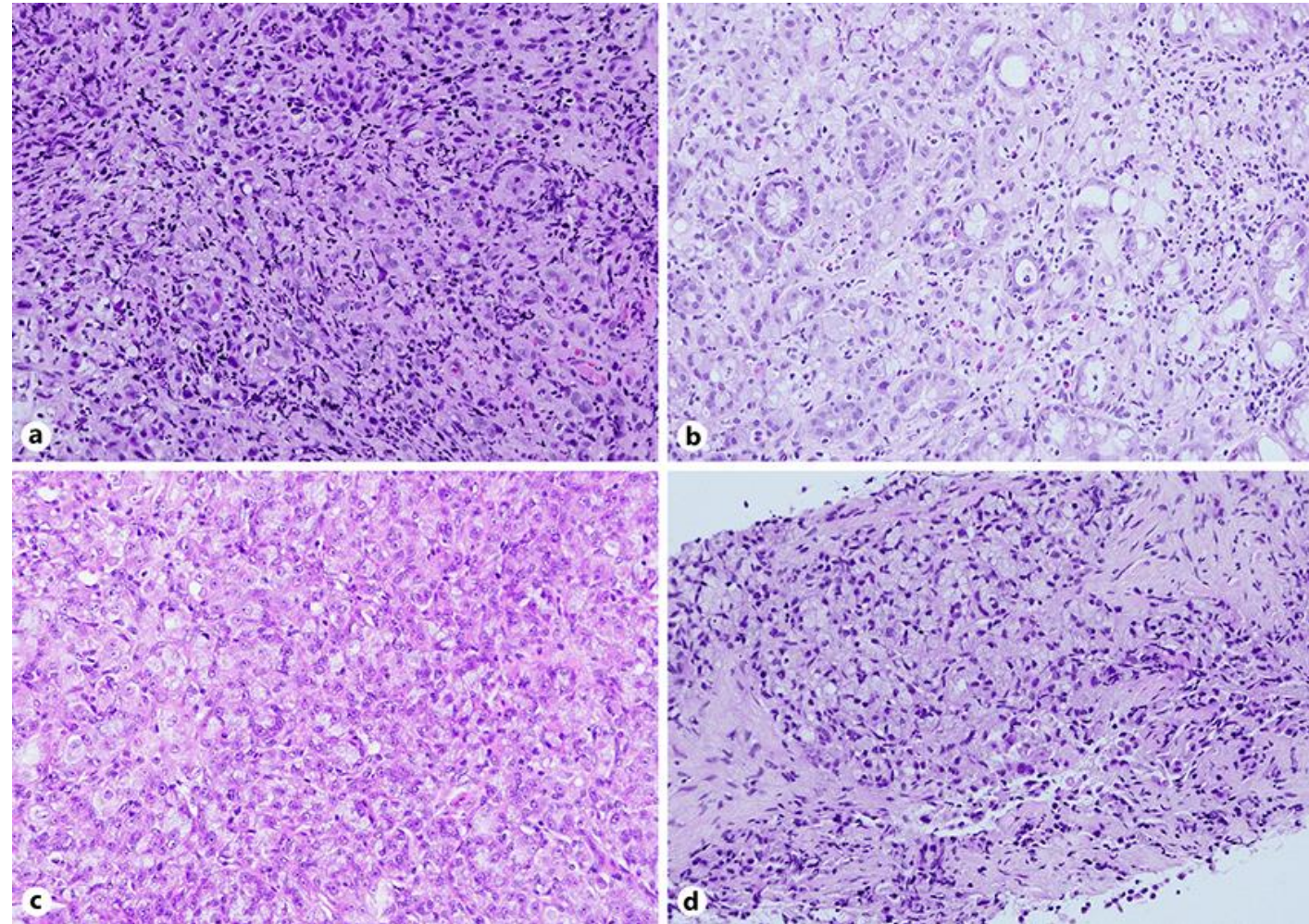

Fig. 3. Pathological findings. Images of hematoxylin and eosin staining of the colonic (a), gastric (b), subcutaneous (c), and pulmonary (d) lesions are shown. All figures have a magnification of $\times 200$. 

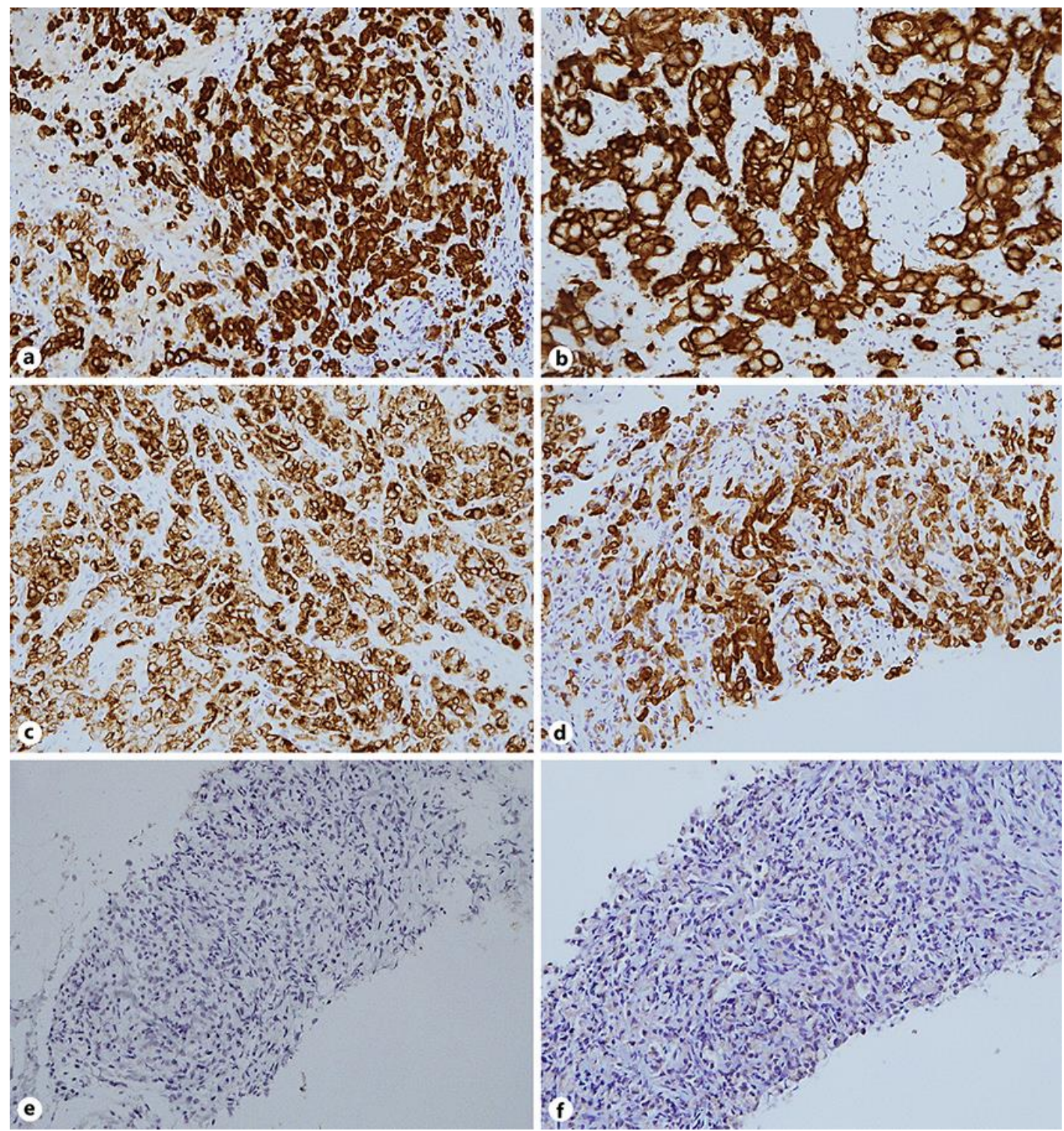

Fig. 4. Immunohistochemical findings. Images of cytokeratin 20 of the colonic (a), gastric (b), subcutaneous (c), and pulmonary (d) lesions are shown. Images of thyroid transcription factor-1 (e) and surfactant Protein $A(f)$ in the pulmonary lesion are shown. All figures have a magnification of $\times 200$. 